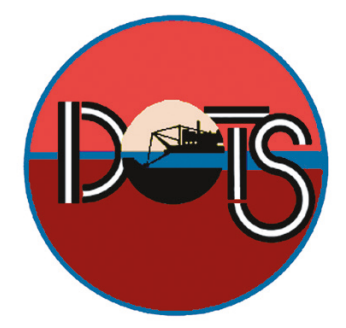

ERDC/TN DOTS-19-1

January 2019

\title{
Monitoring a Nearshore Beneficial Use Site: Application of a Benthic Sled and Video Annotation
}

by Justin Wilkens, Jarod Norton, and G. Curtis Roegner

PURPOSE: This technical note (TN) describes the U.S. Army Corps of Engineers (USACE) Portland Districts (NWP) application of 1) a benthic sled equipped with an image sensor and towed over a nearshore beneficial use site to monitor marine animals, 2) computational software used to annotate the video acquired by the benthic sled, and 3) automation of video annotation.

BACKGROUND: The NWP maintains safe and navigable waterways in Oregon through a variety of dredging projects, including channel deepening, and dredging sandbars. Placement of dredged sediment occurs at preselected, specific geographic areas. One such group of sites are categorized by NWP as nearshore beneficial use sites, these are used for the Mouth of Columbia River Federal Navigation Project (MCR). Approximately 3-5 million cubic yards of sand is dredged annually from the MCR entrance channel to keep the deep-draft federal navigation channel open. Much of the dredged sand is placed at the nearshore beneficial use sites (North Jetty and South Jetty Site, Oregon), this allows natural migration of the dredged sand through the Columbia River littoral cell (Norton et al. 2015). Beneficial use sites are commonly monitored before, during, and after disposal, to evaluate dredge management practices and to avoid potentially adverse effects to the marine environment.

The NWP, in collaboration with the National Oceanic and Atmospheric Administration (NOAA), the U.S. Environmental Protection Agency Region 10, and the Oregon Department of Fish and Wildlife (ODFW), regularly conduct site monitoring of the physical and ecological conditions of the placement sites. Ecological monitoring focuses on the survey of fish and epibenthic invertebrate species distribution and abundance. Surveys are conducted within, and outside the disposal area to assess changes in population or community structure, and to establish diversity indices for comparisons over time. A commonly used survey method to accomplish this goal is a bottom trawl survey, whereby a net is dragged along a preselected part of the ocean floor for a specific time and distance (Zimmermann et al. 2003). The net is then retrieved onto the boat where the aquatic life can be more closely examined and the taxa are sorted. In addition to taxonomical identification, organism weight, length, and condition are often recorded. Traditional trawl surveys are labor and resource intensive, highlighting the opportunity to improve alternative "passive" survey methods.

A towed benthic sled is a passive method that has been used for several decades, this method is useful for evaluating not only the distribution and abundance of marine animals, but in particular their habitat associations (Uzmann et al. 1977; Lauth et al. 2004; Spencer et al. 2005; Stoner et al. 2007; Rooper 2008). A benthic sled is typically fabricated of aluminum or steel pipe and 
flanges to attach equipment like an imaging system and lighting. The sled is towed behind a boat across the sediment surface to collect video of organisms and physical features near the bottom. The benthic sled post-survey analysis usually relies on annotations made by human observers, this is often labor and software intensive. Therefore, long term video collection projects, occurring over many years, often require robust software tools to effectively analyze data sets.

For several years, the NWP has employed NOAA and ODFW custom built benthic sleds equipped with a video system to help monitor marine animals near the sediment surface at NWP's nearshore beneficial use sites. The Video Annotation and Reference System (VARS) (Schlining and Stout 2006), developed and used by the Monterey Bay Aquarium Research Institute (MBARI) for their deep-sea video annotations, was identified by the U. S. Army Engineer Research and Development Center (ERDC) to annotate the underwater video collected at nearshore beneficial use sites.

OBJECTIVES: The objectives of this TN are to 1) describe a benthic sled, 2) provide a brief review of the differences between bottom trawl and benthic sled survey data, 3) describe the VARS software used to view, annotate, and manage video data, and 4) provide a brief review of automated annotation.

BENTHIC SLED: Benthic sleds, or underwater sleds, have been used for several decades for video or image surveys. Sled designs are classified based on where the sled is assigned to operate in the water column as bottom contacting or bottom tending (Rooper 2008). A bottom contacting sled design is most commonly used (Figure 1). This design sinks to the bottom and maintains contact with the bottom while being towed on skids. A bottom tending sled is designed to be semi-buoyant, allowing the user to adjust the sled buoyance to achieve a specific depth. Bottom tending sleds are less conventional survey platforms, requiring some knowledge in control systems, fabrication, and electronics to successfully build, deploy, and operate (Spencer et al. 2005; Rooper 2008). Equipment such as image sensors or lasers for measurement scale can typically be mounted with limited modification to either sled design. Benthic sleds towed by NOAA and ODFW are bottom contacting designs and have been deployed in shallow and deep water $(>70 \mathrm{~m})$. NOAA sled accessories have included a high-resolution camera for the primary data acquisition (data camera, Canon Vixia HF R20 camcorder 1080p) enclosed in a waterproof housing, two light intensity-adjustable floodlights, a navigation camera (Multi SeaCam 2060, Deepsea Power and Light, San Diego, CA, USA) and two laser pointers (SeaLaser 100, Deepsea Power and Light, San Diego, CA, USA) to provide a measurement scale for items of interest in the video field of view. The data camera is internally powered, all other electrical and data transmission to the surface is accomplished via an umbilical coaxial cable. The data camera is usually set to a fixed focus and oriented to acquire video of an approximately 2 meter $^{2}$ area in front of the sled, with the laser pointers positioned near the center of the camera's field of view. 

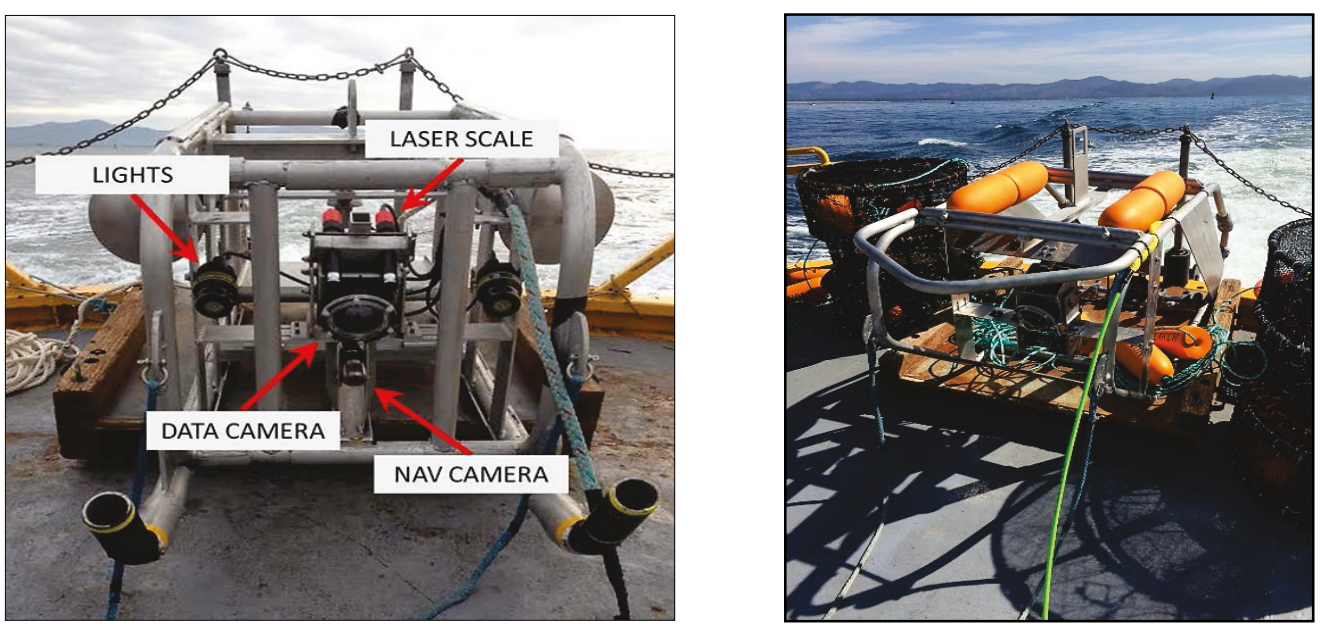

Figure 1. Two bottom contacting benthic sleds used by NOAA (left) and ODFW (right).

To deploy, the sled is hoisted over the boat's stern, and placed into the water with the tow and coaxial cable attached. A depressor weight is attached to the tow cable (approximately $5 \mathrm{~m}$ from the sled). This is used to help reduce the effects of ship movements caused by sea surface conditions. The tow and coaxial cables are dispensed by the crew as the sled descends to the seafloor. Once the sled is on the seafloor, the survey transect starts (Figure 2). To ensure usable image resolution, the sled is towed at speeds of 0.5 to 1 knot. A 500 meter transect will result in a surveyed area of approximately 375 meters $^{2}$, and requires about $30 \mathrm{~min}$ for deployment and recovery. Sled position is estimated from the ships position, and cable deployment length and is recorded by the shipboard Global Positioning Satellite (GPS) system. Benthic sleds provide researchers the flexibility to sample for longer durations in comparison to a bottom trawl survey because animals are not being captured. 


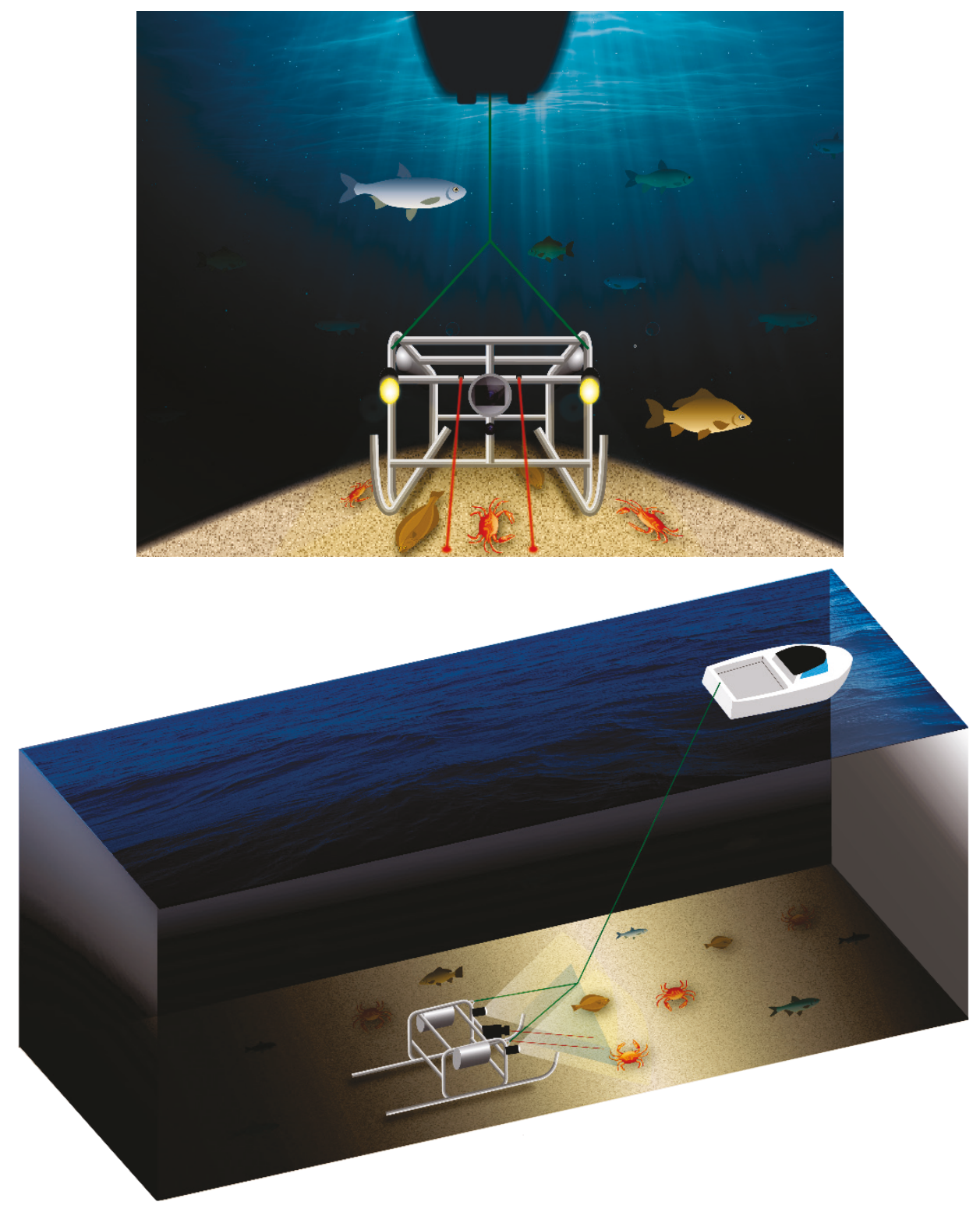

Figure 2. An illustration of a bottom contacting benthic sled towed along the seafloor.

TRAWL AND BENTHIC SLED SURVEY DATA: Comparisons of benthic sled and trawl survey data have highlighted differences in fish densities and species richness (Table 1). In general, the overall mean density of aquatic organisms will often be greater for a benthic sled survey as compared to a trawl survey, but species identification can be limited when using a benthic sled (Spencer et al. 2005; Williams et al. 2015; McIntyre et al. 2015). Spencer et al. (2005) observed video estimates of flatfish density equal to, or higher than, fine-meshed beam trawls, or by divers swimming transects. Similarly, Williams et al. (2015) showed that images obtained from a sled provided significantly higher estimates of megafauna abundance. McIntyre et al. (2015) demonstrated the two survey methods (i.e., trawls versus sleds) can provide different results for certain fish taxa. In particular, differences among methods were apparent for skates and rays, most 
ERDC/TN DOTS-19-1

January 2019

Table 1. A selection of studies showing differences in species density and richness between benthic camera sleds and bottom trawl surveys occurring in the same area.

\begin{tabular}{|c|c|c|c|c|}
\hline \multicolumn{5}{|c|}{ Species Density } \\
\hline \multirow[b]{2}{*}{ Phylum } & \multirow[b]{2}{*}{ Name } & \multicolumn{3}{|c|}{ mean density per $100 \mathrm{~m}^{2}$} \\
\hline & & Bottom trawl & benthic sled w/camera & source \\
\hline \multirow{15}{*}{ Chordata } & Butterfish & 0.05 & - & Uzmann et al. 1977 \\
\hline & Chimaera & $83.9 \times 10^{-5}$ & $12.1 \times 10^{-5}$ & Mclntyre et al. 2015 \\
\hline & Flatfish & 0.16 & 0.79 & Uzmann et al. 1977 \\
\hline & Flatfish & 15 & 94 & Spencer et al. 2005 \\
\hline & Flatfish, age- 0 & 18 & 30 & Spencer et al. 2005 \\
\hline & Flatfish, age-1+ & 3 & 4 & Spencer et al. 2005 \\
\hline & Hakes (red and white) & 0.104 & 0.74 & Uzmann et al. 1977 \\
\hline & herring & 0.020 & - & Uzmann et al. 1977 \\
\hline & Mackerel & 0.027 & - & Uzmann et al. 1977 \\
\hline & Macrourids & $49.7 \times 10^{-5}$ & $18.9 \times 10^{-5}$ & McIntyre et al. 2015 \\
\hline & Molva sp. & $4.3 \times 10^{-5}$ & $6.2 \times 10^{-5}$ & McIntyre et al. 2015 \\
\hline & Mora moro & $9.6 \times 10^{-5}$ & $2.8 \times 10^{-5}$ & Mclntyre et al. 2015 \\
\hline & Sharks & $13.4 \times 10^{-5}$ & $1.4 \times 10^{-5}$ & Mclntyre et al. 2015 \\
\hline & Skates & 0.002 & 0.01 & Uzmann et al. 1977 \\
\hline & Skates and Rays & $5 \times 10^{-6}$ & $6.4 \times 10^{-5}$ & Mclntyre et al. 2015 \\
\hline \multirow{8}{*}{ Arthropoda } & American lobster & 0.015 & 0.09 & Uzmann et al. 1977 \\
\hline & Cancer crabs & 0.02 & 1.66 & Uzmann et al. 1977 \\
\hline & Crabs & 2 & 15 & Spencer et al. 2005 \\
\hline & Crustacea & 21 & 30 & Williams et al. 2015 \\
\hline & Munid crabs & 0.005 & 4.04 & Uzmann et al. 1977 \\
\hline & Munidopsis verrilli & 0.02 & 0.24 & Nybakken et al. 1998 \\
\hline & Paralomis verrilli & 0.07 & 0.20 & Nybakken et al. 1998 \\
\hline & shells & 3 & 13 & Spencer et al. 2005 \\
\hline \multirow{5}{*}{ Echinodermata } & Echinodermata & 21 & 53 & Williams et al. 2015 \\
\hline & Paelopadites confundens & 2.88 & 10.27 & Nybakken et al. 1998 \\
\hline & Pannychia moseleyi & 0.50 & 4.89 & Nybakken et al. 1998 \\
\hline & Tromikosoma panamense & 0.20 & 0.52 & Nybakken et al. 1998 \\
\hline & Benthodytes sanguinolenta & 0.003 & 0.45 & Nybakken et al. 1998 \\
\hline \multirow{4}{*}{ Cnidaria } & \begin{tabular}{|c|} 
Coral \\
\end{tabular} & 11 & 580 & Williams et al. 2015 \\
\hline & Corallimorphus rigidus & 1.44 & 3.29 & Nybakken et al. 1998 \\
\hline & Liponema brevicornis & 0.02 & 0.21 & Nybakken et al. 1998 \\
\hline & Paractinostola faeculenta & 0.009 & 0.51 & Nybakken et al. 1998 \\
\hline Porifera & & 3 & 97 & Williams et al. 2015 \\
\hline \multicolumn{5}{|c|}{ Species Richness } \\
\hline Porifera & $\mathrm{N} / \mathrm{A}$ & 28 & 5 & Williams et al. 2015 \\
\hline Cnidaria & Coral & 40 & 22 & Williams et al. 2015 \\
\hline Arthropoda & Crustacea & 31 & 5 & Williams et al. 2015 \\
\hline Echinodermata & N/A & 60 & 8 & Williams et al. 2015 \\
\hline N/A & $\mathrm{N} / \mathrm{A}$ & 19 & 14 & Uzmann et al. 1977 \\
\hline
\end{tabular}


likely due to the flat body shape which enables them to pass under a trawl more easily. Some taxa, easily sampled and identified by the benthic sled, are not adequately sampled by the trawl because they can pass through the mesh during retrieval of the net (Nybakken et al. 1998). In contrast, species that actively avoided the benthic sled or are cryptic were less abundant than those captured in a trawl (McIntyre et al. 2015; Koslow et al. 1995; Uzmann et al. 1977). Overall, trawls typically detected more species than could be identified in images or video (Spencer et al. 2005; Williams et al. 2015; McIntyre et al. 2015). The authors acknowledge that image resolution and site conditions (e.g., images, video, lighting, and turbidity) can pose challenges for discerning the morphological details needed to identify to species.

The differences in density and identification of aquatic organisms between a trawl survey and benthic sled survey will influence the decision to use one method over the other, depending on project goals. The NWP acknowledges the differences between trawl and benthic sled surveys, and has chosen a sled because it has demonstrated a much lower environmental impact at the sampling site (two skids on the bottom of the sled as compared to the entire length of a trawl net dragging across the bottom), especially when repeatedly sampled (Kincaid and Rose 2017). This is an important consideration when surveying in potentially sensitive areas where sediments have been recently placed and local fauna is recovering (Wilber and Clarke 2007). The megafauna of interest in NWP benthic sled surveys are flatfishes (Pleuronectiformes) and the Dungeness crab (Metacarcinus magister) whose densities in sled surveys have been shown to be equal to, or greater than, trawl surveys (Spencer et al. 2005). In addition to the traditional density and species richness data, the information about habitat associations, or distribution of the animals along a survey transect, is captured when a benthic sled is used. Additional benefits of sleds include the flexibility of the frame design which can be modified to house a variety of sensor types to collect corresponding data (e.g., dissolved oxygen and temperature). A time consuming component of a benthic sled survey is post-processing the video data, this can number in the hundreds of hours. However, video annotation software can be used quickly and effectively to analyze large data sets (i.e., many videos or long duration video files).

VARS: The VARS software (Schlining and Stout 2006) was identified by ERDC to manually annotate the NWP's underwater video collected at the nearshore beneficial use sites. The VARS was developed by MBARI who has been annotating deep-sea videos since the 1980s. The software is designed to allow a human user to manually annotate a video frame, and store the annotation in a database along with frame "grabs" of each annotation, including any ancillary information (e.g., water temperature, depth, size of animal, number of animals, etc.). MBARI created VARS by developing and integrating three applications including a knowledgebase, annotation, and query application. The knowledgebase application contains the data used to annotate videos, thereby helping to standardize data entry. This helps to simplify the interface and save substantial time, especially when querying archived annotations. Administrative permissions (i.e., restrictions) can be established to limit access to the knowledgebase when attempting to change data. The annotation application interacts with the knowledgebase. Commonly used knowledgebase terms can be pinned to the annotation interface which enables faster annotation (Figure 3). When annotating a video file, the VARS built in media player is used to open the file in a separate window (Figure 4). When an annotation is made, the time code of the video file is recorded along with the associated information entered by the annotator (e.g., scientific name, population size, color of sediment, etc.). Depending on project objectives and 
time, anything of interest (i.e., animals and habitat association) in a video frame is eligible for annotation. The query application is used to retrieve the annotations for analysis. Researchers can build queries using a common name, scientific name, or other associated data and export the data to a spreadsheet. This software is available for Windows or Mac OSx and is open source code that can be customized for more specific needs. The software can be downloaded via GitHub (http://hohonuuli.github.io/vars/index.html).

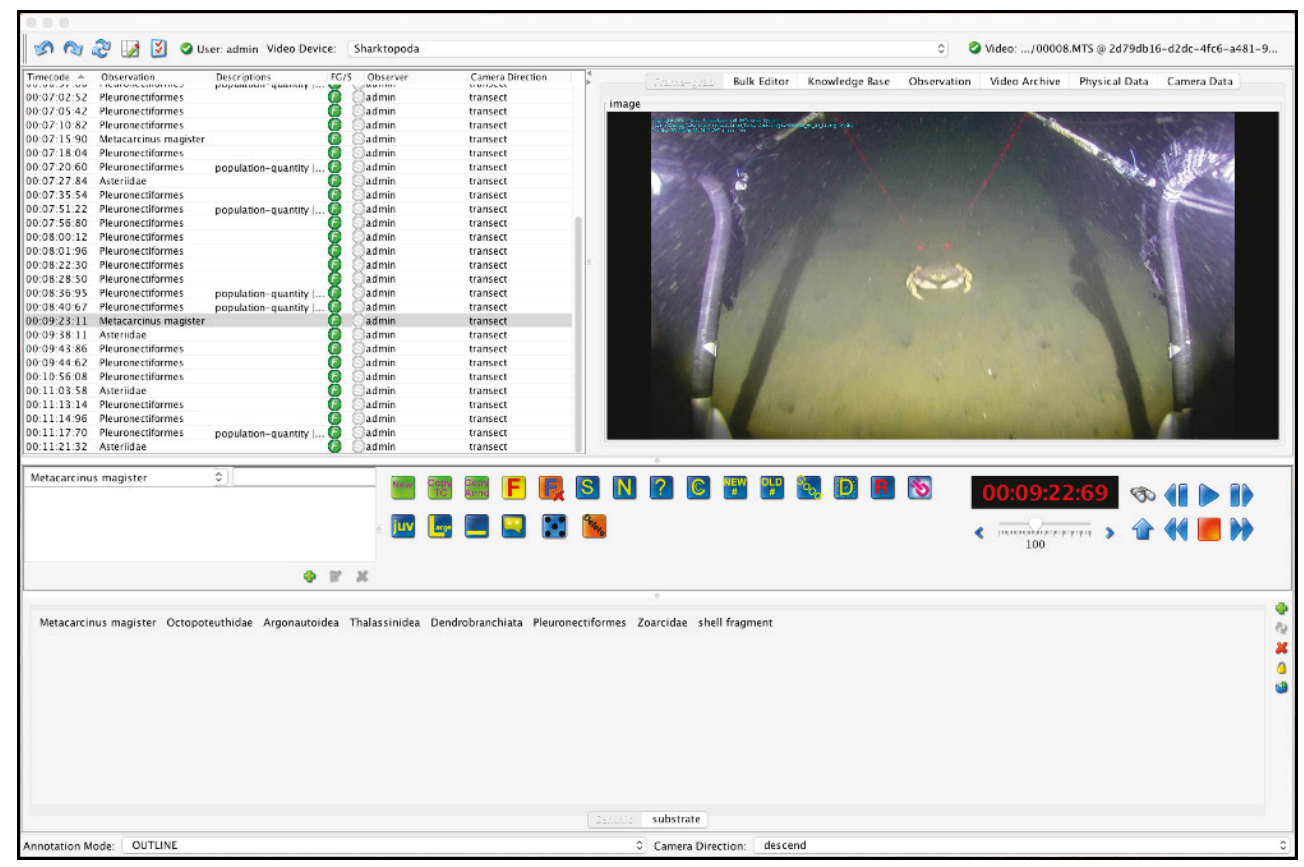

Figure 3. Screenshot of the video annotation application workspace. Record on left (gray highlight) with associated screenshot for annotation on right.

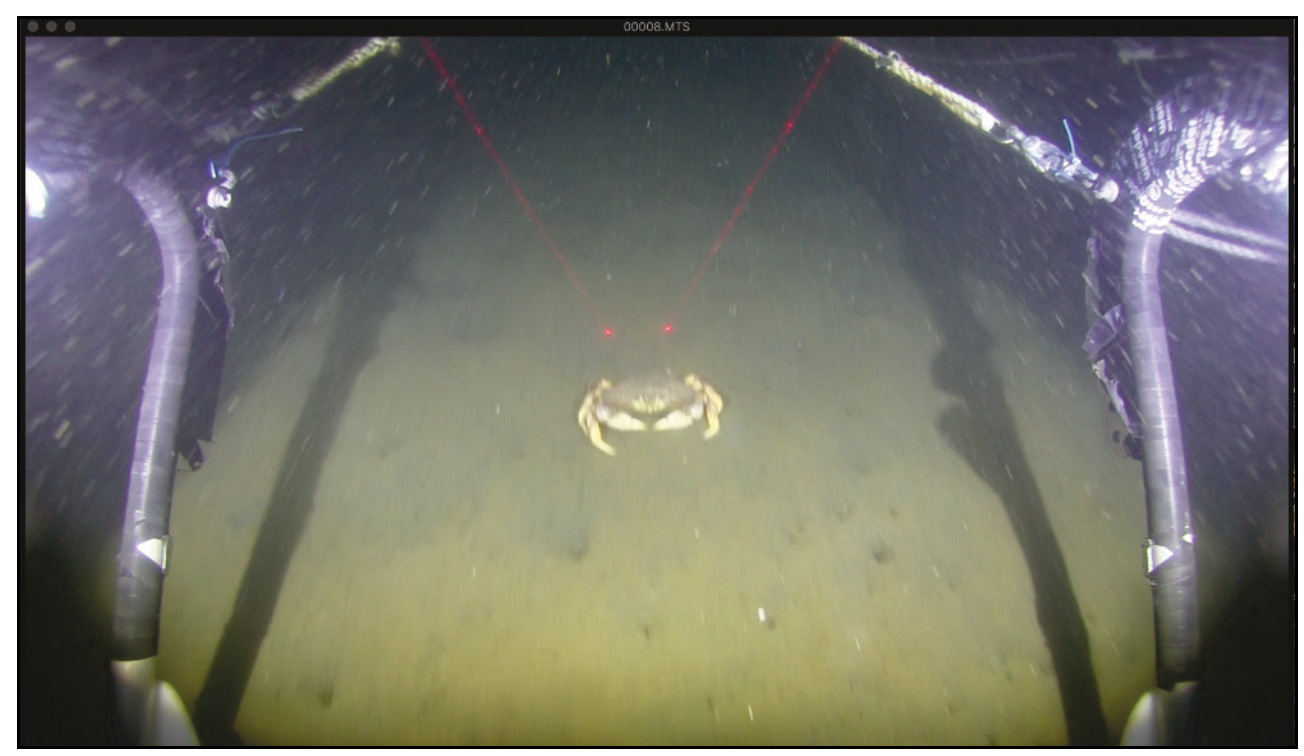

Figure 4. Screenshot of the VARS media player and underwater video footage with two lasers for a measurement scale. 
ANNOTATION AUTOMATION: In the last couple of decades, software programs have been developed in an attempt to semi-automatically or automatically detect, classify, and quantify animals in underwater video (Strachan and Kell 1995; Cline et al. 2007; Spampinato et al. 2010; Shafait et al. 2016; Siddiqui et al. 2017). The goal of this software is to limit the need and cost of a human manually annotating a video or image by automating the process as much as possible and enabling the collection and more efficient processing of many hours of video. Besides being a cost-effective alternative, an automatic recognition system has potential to reduce the environmental impact of the more traditional physically collected samples (e.g., bottom trawls) by improving the usefulness and effectiveness of underwater video surveys which has minimal environmental impact.

However, this opportunity has proven to be especially challenging to take advantage of in an underwater environment, where many non-target objects (i.e., noise) may be present in the video frame at one time. Automated software is usually highly customized, often computer intensive, commonly designed for specific needs, and can require the user to write scripts in order to operate successfully. Nonetheless, software has been developed to take advantage of a variety of algorithms (Spampinato et al. 2008; Godec et al. 2013) to detect objects of interest and then classify and/or quantify them with often times a high degree of success (Shafait et al. 2016; Cline et al. 2007)(Figure 5).

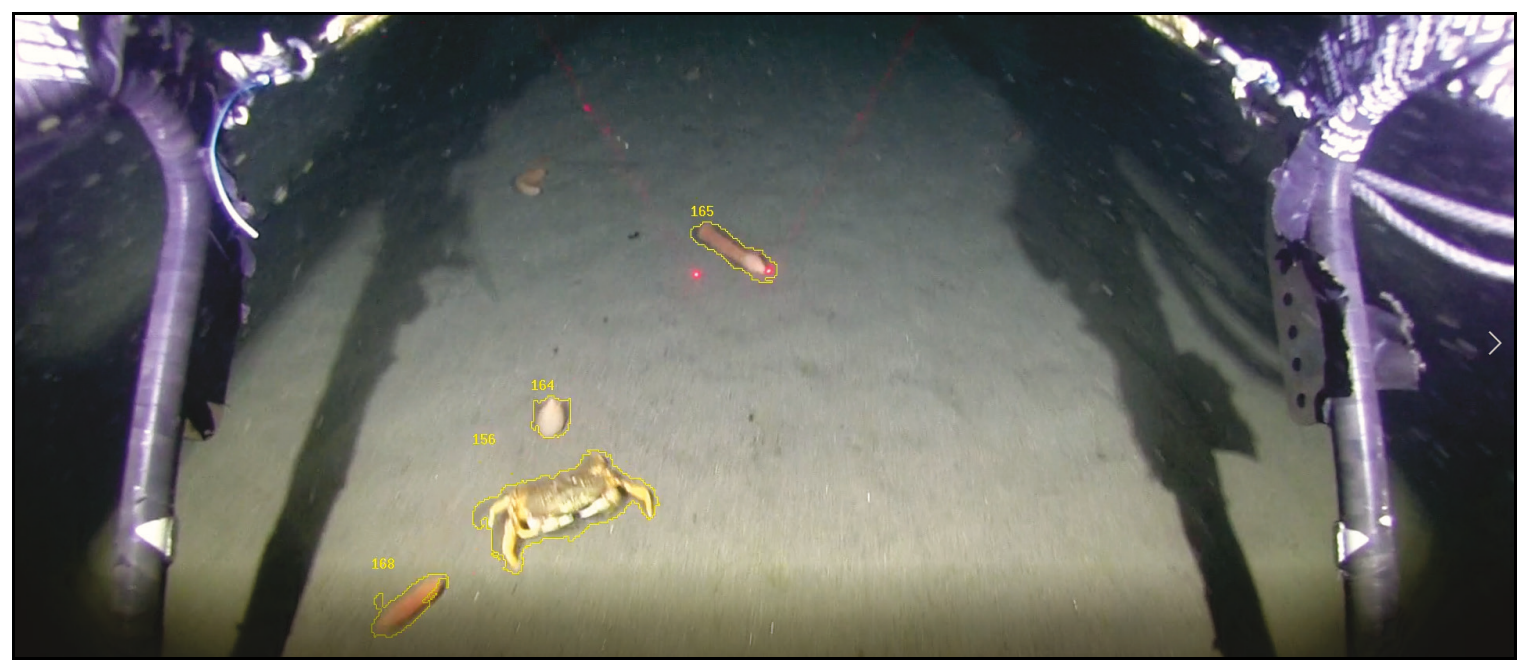

Figure 5. The Automated Visual Event Detection and Classification (AVEDAC) software tracking algorithm (yellow outline and corresponding number) detecting and tracking animals in underwater video acquired from a benthic sled (Cline et al. 2007).

As previously mentioned, the limitations of images, lighting, turbidity and background noise (e.g., other non-target objects) typically limit the software to annotating mostly megafauna, which are easier to detect and classify. Because regulatory and other biological assessments often focus on megafauna, automatic detection and classification systems are desirable and should be an achievable alternative to human annotation of videos or images. Human identification of species is not $100 \%$ accurate (Culverhouse et al. 2007; Peterson 2012), therefore, regardless of the annotation method (machine or human), there will be some degree of error. Determining an acceptable degree of human error for the specific megafauna being surveyed and comparing this 
to machine error, would help to better understand the performance expectations of an automated annotation system and justify efforts to incorporate this technology.

SUMMARY: The benthic sleds are employed by NWP primarily because they have a much lower environmental impact at the sampling site as compared to traditional trawl surveys, especially when repeatedly sampled. In general, benthic sled surveys have greater success in estimating the overall mean density of aquatic organisms as compared to trawl surveys, however, species identification can be limited to megafauna. Manual annotation of video or image data by humans can be achieved by using the VARS software. This video annotation system is well established (i.e., used for decades) and equates to an off-the-shelf software option that can be readily-adapted for a variety of needs and is user friendly. Software designed to automatically or semi-automatically detect, classify, and quantify animals in underwater video with minimal human intervention is improving the opportunity to collect and process more data as well as helping to reduce the need for physically collected samples (i.e., bottom trawls). However, this software is customized, computer intensive, commonly designed for specific needs, and can require the user to write scripts to use successfully. Because regulatory assessments often focus on megafauna, the opportunity to develop and use an automatic detection and classification system should be the goal of future monitoring efforts, which do not require biological samples, because it will decrease cost of human annotation and potentially improve predictive capabilities.

POINTS OF CONTACT: For additional information, contact Justin Wilkens (601-634-2421, Justin.L.Wilkens@usace.army.mil) or Jarod Norton (503-808-4348, Jarod.K.Norton@usace. army.mil) or G. Curtis Roegner (Curtis.Roegner@noaa.gov).

This technical note should be cited as follows:

Wilkens, J. L., J. K. Norton, and G. C. Roegner. 2019. A benthic sled used to monitor a nearshore beneficial use site. DOTS Technical Notes Collection. ERDC/TN DOTS-19-1. Vicksburg, MS: U.S. Army Engineer Research and Development Center. http://el.erdc.usace.army.mil/.

\section{REFERENCES}

Cline, D. E., D. R. Edgington, and J. Mariette. 2007. An automated visual event detection system for cabled observatory video. MTS/IEEE In Oceans 2007 Conference Proceedings. Vancouver: Canada. doi:10.1109/OCEANS.2007.4449253.

Culverhouse, P. F. 2007. Human and machine factors in algae monitoring performance. Ecological Informatics 2(4):361-366.

Godec, M., P. M. Roth, and H. Bischof. 2013. Hough-based tracking of non-rigid objects. Computer Vision and Image Understanding 117(10):1245-1256.

Kincaid, K., and G. Rose. 2017. Effects of closing bottom trawling on fisheries, biodiversity, and fishing communities in a boreal marine ecosystem: The Hawke Box off Labrador, Canada. Canadian Journal of Fisheries and Aquatic Sciences 999:1-13.

Koslow, J. A., R. Kloser, and C. A. Stanley. 1995. Avoidance of a camera system by a deepwater fish, the orange roughy (Hoplostethus atlanticus). Deep-Sea Research part I: Oceanographic Research Papers 42(2):233-244. https://doi.org/10.1016/0967-0637(95)93714-P. 


\section{ERDC/TN DOTS-19-1}

January 2019

Lauth, R. R., Wakefield, W. W., and K. Smith. 2004. Estimating the density of thornyheads, Sebastolobus spp., using a towed video camera sled. Fisheries Research 70:39-48. https://doi.org/10.1016/j.fishres.2004.06.009.

McIntyre, F. D., F. Neat, N. Collie, M. Stewart, and P. G. Fernandes. 2015. Visual surveys can reveal rather different 'pictures' of fish densities: comparison of trawl and video camera surveys in the Rockall Bank, NE Atlantic Ocean. Deep-Sea Research part I: Oceanographic Research Papers 95:67-74. https://doi.org/10.1016/j.dsr.2014.09.005.

Norton, J., R. Moritz, M. Ott, W. Briner, and C. Roegner. 2015. Balancing benefits and impacts when using a nearshore dredged material placement site at the mouth of the Columbia River. In The Proceedings of the Coastal Sediments 2015, San Diego, CA: 11-15 May 2015.

Nybakken, J., S. Craig, L. Smith-Beasley, G. Moreno, A. Summers, and L. Weetman. 1998. Distribution density and relative abundance of benthic invertebrate megafauna from three sites at the base of the continental slope off central California as determined by camera sled and beam trawl. Deep-Sea Research part II: Oceanographic Research Papers 45(8-9):1753-1780. https://doi.org/10.1016/S0967-0645(98)80016-7.

Peterson, S. 2012. The identification process; human and machine (AVEDac) efficiency and effectiveness. White Paper. Retrieved 21 August 2017 from Monterey Bay Aquarium Research Institute: https://www. mbari.org/wpcontent/uploads/2015/10//peterson.pdf.

Rooper, C. N. 2008. Underwater video sleds: versatile and cost effective tools for habitat mapping. In: Reynolds, J. R. and H. G. Greene (ed.), Marine Habitat Mapping Technology for Alaska. University of Alaska Fairbanks, Alaska: Sea Grant College Program 99-107. http://dx.doi.org/10.4027/mhmta.2008.07.

Schlining, B. and N. Jacobsen Stout. 2006. MBARI's video annotation and reference system. In: Proceedings of the Marine Technology Society / Institute of Electrical and Electronics Engineers Oceans Conference Boston, Massachusetts 1-5.

Shafait, F., A. Mian, M. Shortis, B. Ghanem, P. F. Culverhouse, D. Edgington, D. Cline, M. Ravanbakhsh, J. Seager, and E. S. Harvey. 2016. Fish identification from videos captured in uncontrolled underwater environments. ICES Journal of Marine Science 73(10):2737-2746.

Siddiqui, S. A., A. Salman, M. I. Malik, F. Shafait, A. Mian, M. R. Shortis, and E. S. Harvey. 2017. Automatic fish species classification in underwater videos: exploiting pre-trained deep neural network models to compensate for limited labelled data. ICES Journal of Marine Science 75(1):374-389. doi:10.1093/icesjms/fsx109.

Spampinato, C., Y. H. Chen-Burger, G. Nadarajan, and R. B. Fisher. 2008. Detecting, tracking and counting fish in low quality unconstrained underwater videos. VISAPP 2:514-519.

Spampinato, C., D. Giordano, R. D. Salvo, Y. H. Chen-Burger, R. B. Fisher, and G. Nadarajan. 2010. Automatic fish classification for underwater species behavior understanding. Firenze, Italy: ACM Workshop on Analysis and Retrieval of Tracked Events and Motion in Imagery Streams 45-50.

Spencer, M. L., Stoner, A. W. Ryer, C. H. and J. E. Munk. 2005. A towed camera sled for estimating abundance of juvenile flatfishes and habitat characteristics: comparison with beam trawls and divers. Estuarine, Coastal, and Shelf Science 64:497-503.

Stoner, A. W., M. L. Spencer, and C. H. Ryer. 2007. Flatfish-habitat associations in Alaska nursery grounds: Use of continuous video records for multi-scale spatial analysis. Journal of Sea Research 57:137-150.

Strachan, N. J. C., and L. Kell. 1995. A potential method for the differentiation between haddock fish stocks by computer vision using canonical discriminant analysis. ICES Journal of Marine Science 52:145-149. https://doi.org/10.1016/10543139(95)80023-9.

U.S. Army Corps of Engineers. 2015. Engineering and design, dredging and dredged material management. Publication No. EM 1110-2-5025. Proponent CECW-EW. Washington, DC: 31 July 2015. http://www.publications.usace.army.mil/USACE-Publications/Engineer-Manuals/.

Uzmann, J. R., R. A. Cooper, R. B. Theroux, and R. L. Wigley. 1977. Synoptic comparison of three sampling techniques for estimating abundance and distribution of selected megafauna: submersible vs camera sled vs otter trawl. Marine Fisheries Review 39(12):11-19. 
Wilber, D. H. and D. G. Clark. 2007. Defining and assessing benthic recovery following dredging and dredged material disposal. In: R.E. Randall (ed.), Proceedings of the XVIII World Dredging Congress Lake Buena Vista, FL: Newman Printing Co.

Williams, A., F. Althaus, and T. A. Schlacher. 2015. Towed camera imagery and benthic sled catches provide different views of seamount benthic diversity. Limnology and Oceanography Methods 13(2):62-73.

Zimmerman, M., M. E. Wilkins, K. L. Weinberg, R. R. Lauth, and F. R. Shaw. 2003. Influence of improved performance monitoring on the consistency of a bottom trawl survey. ICES Journal of Marine Science 60(4):818-86. https://doi.org/10.1016/S1054-3139(03)00043-2.

NOTE: The contents of this technical note are not to be used for advertising, publication, or promotional purposes. Citation of trade names does not constitute an official endorsement or approval of the use of such products. 